\title{
Article
}

\section{How Do Power Type and Partnership Quality Affect Supply Chain Management Performance?}

\author{
Kwang O. Park ${ }^{1}$, Hwalsik Chang ${ }^{2}$ and Dae Hyun Jung ${ }^{2, *}$ \\ 1 Division of Business, Yeungnam University College, Daegu 42415, Korea; kopark1021@ync.ac.kr \\ 2 School of Business, Pusan National University, Pusan 46241, Korea; hwschang@pusan.ac.kr \\ * Correspondence: jdh@pusan.ac.kr; Tel.: +82-53-650-9333, Fax: +82-53-625-6246
}

\begin{abstract}
A supply chain management (SCM) system is a strategic cooperative that organically integrates all supply chains to improve the performance of a company. The greatest critical success factor of SCM is partnership. Without cooperation between companies, SCM performance is limited. Does this imply, therefore, that companies within the supply chain can achieve mutual transactions equally? If the power between companies is unequal, how does this affect their partnership? The focus of this study is to assess whether power types enhance SCM performance through partnerships. We categorize power types as mediated and non-mediated. Mediated power is categorized based on coercion, reward, and legitimate, while non-mediated power is categorized based on information, expert, and reference. Therefore, this study examines how power types form a causal partnership relationship within the supply chain, and performs an empirical investigation on how the partnerships influence SCM performance.
\end{abstract}

Keywords: SCM; SCM performance; mediated power; non- mediated power; partnership quality

\section{Introduction}

A supply chain management (SCM) system is a strategic cooperative that organically integrates all supply chains to improve the performance of a company [1]. For an effective SCM system, emphasis is placed on securing long-term mutual relationships and partnerships. SCM includes all transportation, storage, and information processing from the raw material stage to the point where the product reaches the final consumer [2-3]. Therefore, SCM can only be accomplished through cooperation and partnership. Companies that efficiently manage SCM systems achieve higher performance in areas such as delivery times, product management, and customer service [4]. Companies with successful SCM system operations realized a 17\% increase in revenue, a 36-day stock decrease, and 97\% shipment growth [5]. A study by Tony et al. (2009) [6] found that revenues from the sale of the SCM system were estimated to increase by 7\% a year, rising from $\$ 6.5$ billion in 2007 to $\$ 9.2$ billion in 2012 .

The studies on SCM systems thus far are categorized based on whether the focus is on the SCM system as the critical success factor [7], determinants of SCM adoption [8], the supply chain process integration [9], the SCM partnership [10], or the SCM promotion strategy [11].

The greatest critical success factor (CSF) of SCM is partnership. Without cooperation between companies, SCM performance is limited because the success of SCM is dependent on the close cooperation of participating companies [12]. A company cannot be independent, and mutual partnership is strengthened through SCM $[13,14]$. SCM can increase mutual benefits by eliminating extraneous factors between the supplier and the buyer, or between partner companies.

Does that imply, therefore, that companies within the supply chain can achieve mutual transactions equally? If the power between companies is unequal, how does this affect their partnership? The exploration of partnership power types as a preceding factor that can influence SCM performance is an important component of SCM research. The success of SCM system based on power type benefits the workplace. Attempts to study power types and SCM performance from various perspectives are highly valuable. 
The focus of this study is to assess whether power types enhance SCM performance through partnerships. We categorize power types as mediated power and non-mediated power based on the study of Ke et al. (2009) [15]. Mediated power can be categorized based on coercion power, reward power, and legitimate power while non-mediated power can be categorized based on information power, expert power, and reference power. Therefore, this study examines how power types form a causal relationship among partnerships within the supply chain and performs an empirical investigation on the influence of power types on SCM performance.

In this context, we devised a conceptual research model composed of four constructs shown in Figure 1 and investigated how the SCM performance is influenced by two major factors- power and partnership quality.

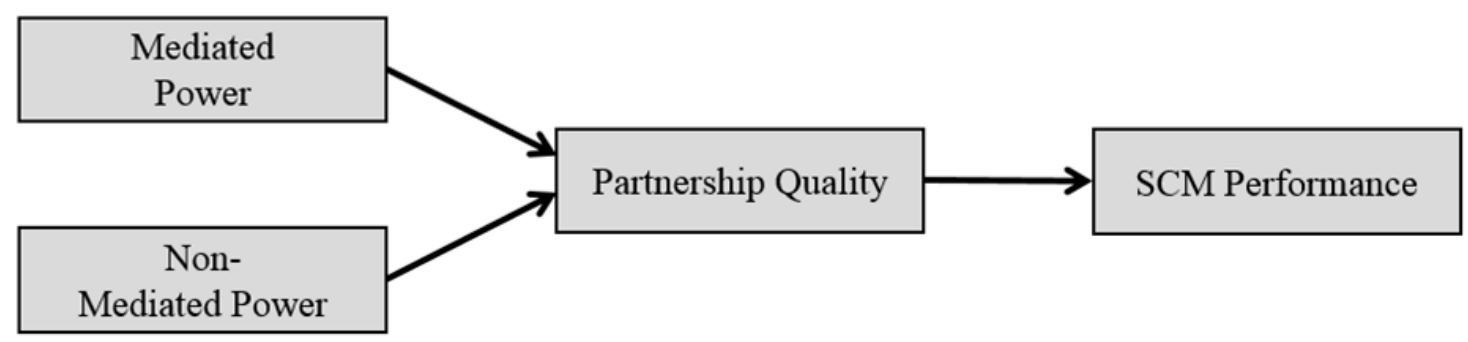

Figure 1. Conceptual Research Model.

SCM, ideally, achieves shared growth between partner companies and sustains a consistent and amicable cooperative relationship. An SCM system should also eliminate imbalances in power to maintain an efficient cooperative relationship. Companies cannot continue to be competitive without considering the supply chain because of constant global environmental changes and uncertainties. Therefore, companies must maintain amicable partnerships while staying competitive [16].

To maintain a consistent transactional relationship, the assessment and management of the various obstructive factors between partners that can occur from an imbalance of power within the supply chain are required. Additionally, in-depth research on power can establish a scientific basis from which to examine the economic paradigm of change and the ways that partner companies adjust. We find various conclusions by presenting practical points after assessing power types and investigating SCM relationships.

Although many studies have addressed SCM, few examine the subject of power. Therefore, this study determines the influence of supply chain companies' power on partnership quality and SCM performance.

In order to empirically test our research model, we developed an instrument and conducted a survey with 124 companies that practice SCM in South Korea. Most studies on information systems (IS) use data for U.S. companies because the U.S. plays a predominant leadership role in various social and business fields. Although the U.S. has the most advanced IS, there is a need for international studies. Some countries have developed to the same degree as the U.S. through IT and IS.

A report by Robert (2009) [17] measured the IT human capital index of 66 nations and reported that South Korea ranked second with 58.9 points only to the U.S. with 75.6 points. In addition, the competitiveness index of South Korea's IT industry was ranked sixth.

Thus, this gradually globalizing market should be studied from an international perspective. Furthermore, researchers need a more comprehensive approach to analyze companies that currently engage in global business.

The remainder of this paper includes a review of the theoretical background, the research model and hypotheses, the model structure, and a report of the findings of the study. In the final section, we discuss the findings, implications, and limitations of the study. 


\section{Theoretical Background}

\subsection{Power}

French et al. (1959) [18] were the first to mention power between companies. Power can be defined as the source enterprise's ability to influence the intentions or actions of an opposing company. Power is also defined as the potential to influence another or the ability to make another act in a desired way. Table 1 is an example of a list existing study on power.

Table 1. Major literature on power and issues covered.

\begin{tabular}{lll}
\hline References & Major Studies on Power Used in the Study \\
\hline \multirow{2}{*}{ Ke et al. (2009) [15] } & Mediated Power & Coercion, Reward, Legitimate \\
& Non-mediated Power & Information, Expert, Reference \\
Zhao et al. (2013) [9] & Mediated Power & Coercion, Reward \\
& Non-mediated Power & Information, Expert, Legitimate \\
Flynn et al. (2008) [19] & Mediated Power & Coercion, Reward \\
& Non-mediated Power & Information, Expert, Legitimate \\
& Non-mediated Power & Expert, Reference \\
Benton \& Maloni (2005) [20] & Coercive-mediated Power & Coercion, Legitimate \\
& Reward-mediated Power & Reward \\
\hline
\end{tabular}

Power that influences the members of an organization or a partner company appears in various forms. The most widely known forms originated from French et al. (1959) [18], who included "coercion power," "reward power," and "legitimate power" as power from an official standpoint, and "information power," "expert power," and "reference power" are categories of power from a personal attribute standpoint.

- Coercion power is the power to induce fear of punishment when subordinates do not meet a certain expectation, thus stimulating acquiescence to the commands of the power holder. Coercion power can also be strengthened by threatening or warning that an undesirable or disadvantageous result will occur if the subordinate does not abide by the requests, policies, or rules of the transactor [9].

- Reward power is the power that is formed by the understanding that the power holder can offer the subordinate a reward. The greater is the ability to reward, the stronger is the effect of the reward [20].

- Legitimate power is power based on the power holder's standing and the power that results from the partner company's obligation to acquiesce to that standing. Therefore, the effect of legitimate power is dependent on acceptance and consent through the involved party's tacit understanding [21].

- Expert power is influenced by respect for the power holder's specialized technology or knowledge. Therefore, expert power is valuable when an important issue is resolved. Expert power provides expertise for optimal decisions and reliable advice [19].

- Information power refers to a situation where power is granted by the ability to control the access or distribution of information despite no expertise [22].

- Reference power is power attained when the subordinate has equal standing with the power holder and occurs through the partner company's attractiveness or charisma. The strongest form of reference power is influence on the subordinate to assume equality with the partner company [15].

Ke et al. (2009) [15] divided power types into mediated power and non-mediated power. Mediated power includes coercion, reward, and legitimate. Coercion power is defined by the power to enforce punishment when the partner company does not cooperate. Reward is the power to provide rewards when the partner company's requests are satisfied. Legitimate power refers to legal power to influence the partner company.

Non-mediated power includes information, expert, and reference. Information power is the power to provide information to the partner that could not be obtained otherwise. Expert power is 
specialized knowledge or technology that is beneficial and received through the partner company. Reference power is the maintenance of a close relationship between partner companies (Figure 2).
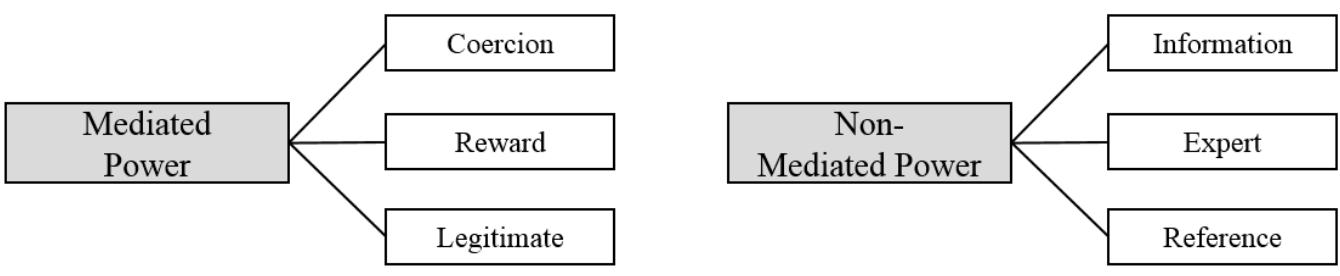

Figure 2. Power Type (Ke et al. (2009) [15]).

Of course, power can be classified into several types. However, this paper discusses the power within a supply chain. The "mediated," the classification standard in this paper, implies affecting the behaviors of partners. Thus, the fact that decision making and relationships are affected by the power of partner companies within a supply chain has the strongest overlap with the purpose of this paper. Thus, this paper was based on the research of Ke et al. (2009) who study the power in a supply chain.

In this research, power types are examined based on coercion, reward, legitimate, information, expert, and reference. This study was conceptualized based on the research results of Ke et al. (2009) [15]. Power types are categorized as mediated power and non-mediated power, and this study focuses on a discussion of the categories that result from legal force.

\subsection{Partnership Quality}

Partnership is a CSF in establishing a strategy between companies. Companies can maximize profits, achieve their respective goals, and secure a competitive edge through partnership. Mentzer et al.(2000) [23] argued that partnerships are necessary in strategic tasks related to stock decreases and the improvement of inefficiency in the supply chain such as operational work, new product development, and building shipment systems.

The relationships in social exchange theory and SCM, on which this study is based, are as follows. Social exchange theory was first developed by Homans (1958) [24]. According to this theory, all humans display different actions based on a subjective costs and benefit analysis. The basic principle of the social exchange theory is that a consistent transactional relationship occurs with the understanding that mutual benefits result from the process of exchange and transactions between organizations.

Figure 3 shows that Lee \& Kim (1999) [25] used three factors based on social exchange theory: determinants for partnership quality, partnership quality, and outsourcing success. Of these, five factors measure partnership quality: trust, business understanding, the share of benefit and risk, conflict, and commitment. Trust refers to faith in the other party's actions with a relationship. It is the expectation that the actions that are entrusted to the other party will be accomplished in good faith. Trust between partner companies requires mutual trust and reliance, and the belief that the partner company will create positive results [26]. Business understanding is defined as the degree of understanding regarding the partner company's goals and policies. In some studies $[27,28]$, this is defined as the mutual understanding of broader business issues. The share of benefit and risk between companies in a partnership is the appropriate distribution of benefits and risks among the company and the partnership company through a common goal. To gain a competitive advantage through effective SCM operation, a long-term relationship is maintained by sharing benefit and risk [29]. Conflict significantly influences the success of an SCM system. When a conflict is not resolved, it can negatively influence the partnership between companies. Therefore, to create a partnership, the degree of conflict in a working relationship must be reduced [30]. Commitment is an expression of the determination to maintain a long-term transactional relationship. It represents voluntary effort to maintain a long-term relationship between companies. Therefore, commitment suppresses opportunistic actions and switching of partners to reduce costs because there is a desire to maintain a long-term transactional relationship [31]. 


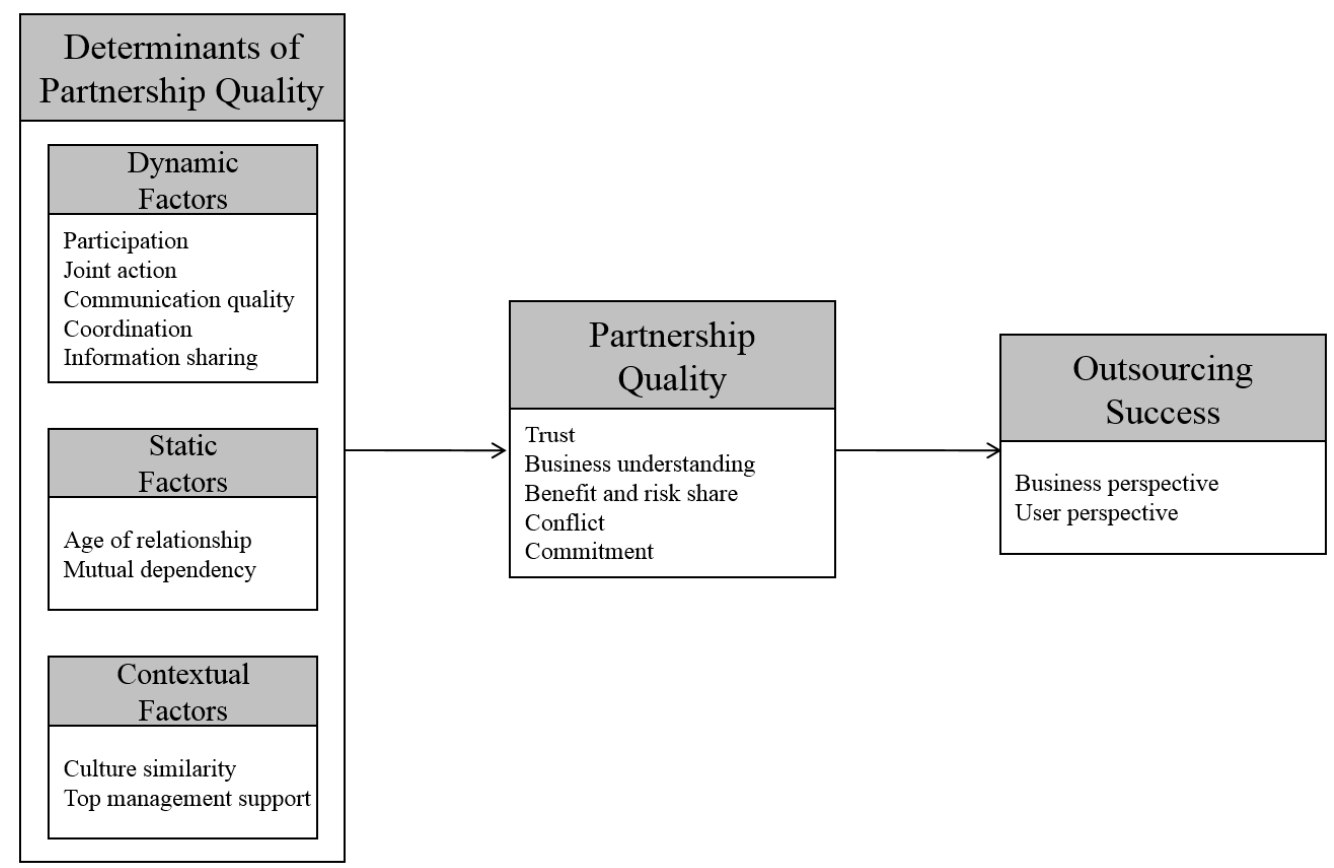

Figure 3. Effect of Partnership Quality on IS Outsourcing Success.

\subsection{SCM Performance}

The studies on SCM performance conducted thus far can be divided into four categories. First, financial performance was measured using financial variables such as sales, the rate of earnings, and the rate of investment earnings, which are conventional factors for financial performance [32,33]. Second, non-financial performance was measured by factors such as customer satisfaction and customer maintenance [34,35]. Third, the performance of SCM systems was divided and measured from a financial, customer, internal business processes, and a learning and growth perspective using a BSC performance index method [36,37]. Lastly, we present a performance index table by level using five different processes: plan, source, make, deliver, and return using the SCOR model.

Ultimately, SCM performance can be defined as the degree of quantitative and qualitative performance that matches the strategic goals set within the supply chain because of the implementation of an SCM system [13]. However, while SCM systems are used throughout all industries, insufficient studies on SCM performance measurement are reviewed because the studies tend to focus on the theory and practice of SCM system.

Therefore, this study measures SCM performance by reorganizing financial studies, nonfinancial studies, the BSC methodology, and the SCOR methodology that were used to measure SCM performance. We measure SCM performance using the four categories of quality performance, cost, delivery, and decision.

- Quality performance: Degree of quality of the parts and products enhanced after the innovation of the product manufacturing and distribution process due to the implementation of the SCM system.

- Cost performance: Degree of the reduced cost within a supply chain through the shortening of the manufacturing, distribution, and inventory processes due to the implementation of the SCM system.

- Delivery performance: Degree of success in meeting promised deadlines and quality demands after the implementation of the SCM system.

- Decision performance: Degree of improvement in terms of faster and better decision making after the implementation of the SCM system. 


\section{Research Model and Hypotheses}

This study is based on preceding studies on power types and SCM performance. Figure 4 shows the study model and establishes the research hypotheses. Power types were categorized as mediated power and non-mediated power. Mediated power was categorized based on coercion, reward, and legitimate while non-mediated power was categorized based on information, expert, and reference [15]. Therefore, this study examines the influence of mutual, reciprocal human relationships among power types on SCM performance through partnership quality.

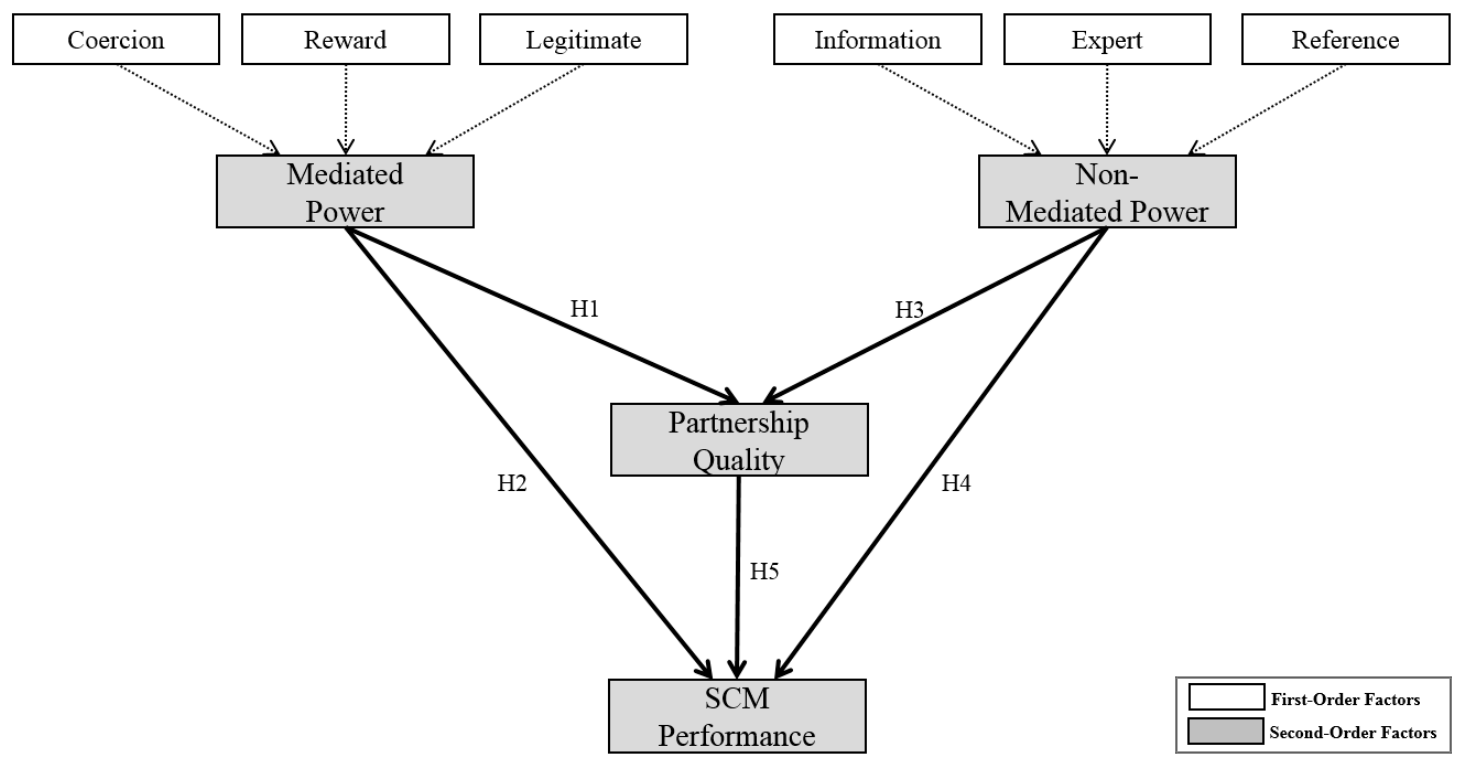

Figure 4. Research model.

\subsection{Hypotheses Development}

Mediated power can be a means to ensure compliance from the partner company. However, strong mediated power can also be a factor that induces a negative impact on the partnership quality [20]. Although mediated power might offer short-term, partial economic gain, it can also decrease the social satisfaction of partner companies. Based on the above discussion, mediated power is hypothesized (Hypothesis 1) to influence partnership quality [19].

Hypothesis 1: Mediated power influences partnership quality.

Establishing a relationship based on an organization's strong leadership can maintain a consistent supply chain relationship [21]. However, when a new system is occasionally implemented, we believe that strong leadership induces short-term success of the system. Therefore, further examination of the influence of mediated power on SCM performance is required. Based on the above discussion, mediated power is hypothesized (Hypothesis 2) to influence SCM performance.

Hypothesis 2: Mediated power influences SCM performance.

Non-mediated power may not be coercive, but it is a factor that maintains a consistent cooperative relationship. Non-mediated power decreases conflict in the relationship between organizations [9]. Therefore, non-mediated power is hypothesized (Hypothesis 3) to influence partnership quality.

Hypothesis 3: Non-mediated power influences partnership quality.

Non-mediated power increases the degree of cooperation among organizations through the process of sharing the value of the partner company [19]. The effort to find a shared point of agreement can play a positive role in SCM operation [13]. Therefore, non-mediated power based on 
creating equal values can maximize SCM performance. Based on the above discussion, non-mediated power is hypothesized (Hypothesis 4) to influence SCM performance.

Hypothesis 4: Non-mediated power influences SCM performance.

Building a trusting relationship between partner companies is a precursor to the successful fulfillment of SCM. SCM can result in more long-term relationships when the common benefit objective is based on the partnership of participating companies. Companies in a partnership based on trust will work to maintain a mutual and productive relationship [30]. This is linked to SCM performance. Therefore, partnership quality is hypothesized (Hypothesis 5) to influence SCM performance.

\section{Hypothesis 5: Partnership quality influences SCM performance.}

\subsection{Sample and Data Collection}

Table 2 shows the operational definition of variables and measurement items based on preceding research. The definitions have been revised and reconstructed to fit the context of this study through statements that ensure the reliability and validity of each measurement item.

- Coercion: Regulations to Force a Company to Adopt Its Partner Company's Requests.

- Reward: Reward for not Accepting the Partner Company's Suggestions.

- Legitimate: Legal Grounds for Accepting the Partner Company's Requests.

- Expert: Benefits of the Partner Company's Expertise to My Company.

- Information: Value of Information Held by the Partner Company.

- Reference: The Degree of Excellence in Culture that can Influence My Company's Attitude and Actions.

- Partnership Quality: Mutual Trust that can Maintain Consistent Transactions with the Partner Company.

- SCM Performance: Degree of Quantitative and Qualitative Performance that Match the Strategic Goals within the Supply Chain in SCM Implementation.

We conducted a survey that was formed based on an existing study, shown in Table 2, to verify the research model and hypotheses in the analysis. To perform the survey systematically, questionnaires were sent to SCM experts and a pilot test was completed. Subsequently, questionnaires were sent to target firms in the primary process to obtain recommendations for managers or supervisors who could respond to the survey questions and conduct the questionnaire. Respondents were selected based on the recommendations from the primary process, and to ensure that the questionnaires included in the study were from respondents who were clearly aware of IS operation in all entire firms. Firms listed on Korea Composite Stock Price Index (KOSPI), which have implemented and used SCM system for a year or more, were selected as survey targets in this study. To collect survey data, an invitation to participate in the survey was extended by phone, email, or in person, and 250 questionnaires were distributed between May and July 2016. We received 124 usable responses for a response rate of $49.6 \%$. Among them, 124 questionnaires were used for analysis. Statistical analysis was conducted using SPSS 21.0 (SPSS: Chicago, IL, USA) and SMART-PLS 3.0 (SmartPLS: Hamburg, Germany).

We used partial least squares (PLS) because this method allows latent constructs to be modeled either as reflective or formative indicators as was the case with our data [38]. Another consideration for the use of PLS was the sample size because PLS imposes less stringent requirements on sample size for analysis than structural equation modeling [39]. Table 3 summarizes the profiles and demographics of the companies that participated in the study. 
Table 2. Research constructs and operationalization.

\begin{tabular}{|c|c|c|c|}
\hline Cor & truct & Items & References \\
\hline \multirow{10}{*}{$\begin{array}{l}\text { Mediated } \\
\text { Power }\end{array}$} & \multirow{3}{*}{ Coercion } & I will be in a bad situation if I do not comply with the partner company's suggestions. & \multirow{10}{*}{$\begin{array}{l}\text { Ke e t al. (2009) [15]; } \\
\text { Flynn et al. (2008) } \\
\text { [19]; Benton \& } \\
\text { Maloni, (2005) [20] } \\
\text { Maloni \& Benton } \\
\text { (2000) [21] }\end{array}$} \\
\hline & & I will be in an undesirable situation if I do not accept the partner company's requests. & \\
\hline & & I will be at a business disadvantage if I do not accept the partner company's requests. & \\
\hline & \multirow{3}{*}{ Reward } & It is difficult to receive incentives if I do not accept the partner company's suggestions. & \\
\hline & & $\begin{array}{l}\text { It is difficult to receive financial benefits if I do not accept the partner company's } \\
\text { suggestions. }\end{array}$ & \\
\hline & & $\begin{array}{l}\text { It is difficult to take part in new businesses if I do not accept the partner company's } \\
\text { suggestions. }\end{array}$ & \\
\hline & \multirow{4}{*}{ Legitimate } & The contract states that I must accept the partner company's suggestions. & \\
\hline & & I am obligated to accept the partner company's suggestions. & \\
\hline & & $\begin{array}{l}\text { We have established a relationship whereby I must accept the partner company's } \\
\text { requests. }\end{array}$ & \\
\hline & & I am obligated to accept the partner company's requests. & \\
\hline \multirow{12}{*}{$\begin{array}{l}\text { Non- } \\
\text { mediated } \\
\text { Power }\end{array}$} & \multirow{4}{*}{$\begin{array}{l}\text { Informatio } \\
\mathrm{n}\end{array}$} & The partner company can offer knowledge that is beneficial to our company. & \multirow{12}{*}{$\begin{array}{l}\text { Zhao et al. (2013) } \\
\text { [9]; Ke et al. (2009) } \\
\text { [15]; Sahin \& } \\
\text { Robinsonet (2002) } \\
\text { [22] }\end{array}$} \\
\hline & & The partner company can offer experience that is beneficial to our company. & \\
\hline & & The partner company can offer advice that is beneficial to our company. & \\
\hline & & The partner company can offer judgments that are beneficial to our company. & \\
\hline & \multirow{4}{*}{ Expert } & The partner company can offer useful information to our company. & \\
\hline & & The work method that the partner company desires can be helpful to our company. & \\
\hline & & $\begin{array}{l}\text { The partner company's judgments are reflected in our company's work because they } \\
\text { are reasonable. }\end{array}$ & \\
\hline & & The partner company offers information that our company can trust. & \\
\hline & \multirow{4}{*}{ Reference } & The partner company's values are exemplary. & \\
\hline & & The partner company's decisions are exemplary. & \\
\hline & & The partner company's operational methods are exemplary. & \\
\hline & & Assuming a similar culture to that of the partner company is advantageous. & \\
\hline \multirow{5}{*}{\multicolumn{2}{|c|}{ Partnership Quality }} & The partner company and our company have a deep, mutual trust. & \multirow{5}{*}{$\begin{array}{l}\text { Kwon \& Suh (2004) } \\
\text { [30]; Quinn } \\
\text { (2000)[28]; Lee \& } \\
\text { Kim (1999) [25] }\end{array}$} \\
\hline & & $\begin{array}{l}\text { The partner company and our company both understand the task processing } \\
\text { procedure. }\end{array}$ & \\
\hline & & The partner company and our company share the risks and benefits. & \\
\hline & & The partner company and our company both work to reduce divisions. & \\
\hline & & The partner company and our company acknowledge each other's value. & \\
\hline \multirow{4}{*}{\multicolumn{2}{|c|}{ SCM Performance }} & $\begin{array}{l}\text { The quality of parts and products has improved through an innovative production and } \\
\text { distribution process from the implementation of the SCM system. }\end{array}$ & \multirow{4}{*}{$\begin{array}{l}\text { Myhr \& Spekman } \\
\text { (2005) [13]; } \\
\text { Frohlich \& } \\
\text { - Westbrook (2001) } \\
\text { [32]; Hoque \& } \\
\text { - James (2000)[34] }\end{array}$} \\
\hline & & $\begin{array}{l}\text { We have reduced costs within the supply chain by shortening production, distribution, } \\
\text { and stock processes while implementing the SCM system. }\end{array}$ & \\
\hline & & $\begin{array}{l}\text { We are better able to meet the promised payment date and demanded quantities by } \\
\text { implementing the SCM system. }\end{array}$ & \\
\hline & & can make quicker and better decisions by implementing the SCM system. & \\
\hline
\end{tabular}


Table 3. Profiles of companies and respondents.

\begin{tabular}{ccc}
\hline & Frequency & Percent (\%) \\
\hline Industry & & \\
Manufacturing/engineering & 39 & 31.5 \\
Services and utilities & 34 & 27.4 \\
Transportation and logistics & 26 & 21.0 \\
Retailing and wholesale & 25 & 20.1 \\
\hline Number of employees & & \\
Less than 100 & 34 & 27.4 \\
101-500 & 41 & 33.1 \\
501-1000 & 7 & 5.6 \\
More than 1000 & 42 & 33.9 \\
\hline Age of SCM (years) & & \\
$1-2$ & 2 & 1.6 \\
$2-3$ & 16 & 12.9 \\
$3-4$ & 26 & 21.0 \\
$4-5$ & 13 & 10.5 \\
Over 5 & 67 & 54.0 \\
\hline Title of respondent & & \\
Assistant manager & 44 & 35.5 \\
Manager & 49 & 39.5 \\
General manager & 26 & 21.0 \\
Executive director & 5 & 4.0 \\
\hline
\end{tabular}

\subsection{Measurement Model}

Confirmatory factor analysis verified the validity of the model proposed in this study. Table 4 briefly indicates the analytic result, the mean, and standard deviation of each variable. The values of all variables exceed the standard value of 0.5 (shaded number).

Goodness of fit for a model is determined based on Composite Reliability (CR) and Average Variance Extracted (AVE). Convergent validity is ensured if the CR value is 0.7 or over, or if the AVE value is 0.5 or over. Table 5 indicates that the $C R$ values exceed the standard value of 0.7 and that the AVE values exceed the standard value of 0.5; thus, convergent validity is ensured. The Cronbach's $\alpha$ also exceeds the standard value of 0.7 .

A discriminant validity compares a correlation between the AVE and variable to determine if the square root of AVE is higher than the correlation [40]. Table 6 shows that the square root of AVE is higher than the correlation between variables. This implies that discriminant validity among the entire constructs is ensured.

Moreover, multicollinearity was analyzed using the variance inflation factor (VIF) and Tolerance methods. Table 7 that shows the result of VIF values and Tolerance values. The analytic result indicates that multicollinearity among these variables poses no problem. Typically, a problem of multicollinearity does not occur when the VIF value is 10 or lower, and the Tolerance value is 0.3 or higher. 
Table 4. Results of confirmatory factor analysis (each item is measured with a seven-point Likert type scale).

\begin{tabular}{|c|c|c|c|c|c|c|c|c|c|}
\hline Item & Expert & Reference & $\begin{array}{l}\text { Partnership } \\
\text { Quality }\end{array}$ & SCM Performance & Legitimate & Reward & Coercion & Information & Mean (S.D.) \\
\hline $\mathrm{CO} 1$ & 0.090 & 0.150 & -0.091 & -0.053 & 0.257 & 0.262 & 0.788 & 0.056 & \multirow{3}{*}{$4.30(1.56)$} \\
\hline $\mathrm{CO} 2$ & 0.086 & 0.023 & -0.030 & -0.120 & 0.291 & 0.324 & 0.822 & -0.060 & \\
\hline $\mathrm{CO} 3$ & 0.038 & 0.068 & -0.075 & -0.070 & 0.143 & 0.401 & 0.794 & -0.014 & \\
\hline RE1 & -0.038 & 0.118 & -0.066 & -0.017 & 0.237 & 0.858 & 0.283 & 0.023 & \multirow{3}{*}{$3.90(1.44)$} \\
\hline RE2 & -0.032 & 0.100 & -0.102 & -0.026 & 0.187 & 0.872 & 0.299 & 0.098 & \\
\hline RE3 & 0.037 & 0.001 & -0.059 & -0.041 & 0.175 & 0.769 & 0.441 & 0.039 & \\
\hline LE1 & 0.041 & 0.056 & -0.041 & 0.088 & 0.819 & 0.131 & 0.137 & 0.121 & \multirow{4}{*}{$3.90(1.44)$} \\
\hline LE2 & 0.120 & 0.097 & 0.024 & 0.147 & 0.877 & 0.181 & 0.123 & 0.050 & \\
\hline LE3 & 0.141 & 0.069 & 0.113 & 0.000 & 0.847 & 0.099 & 0.269 & -0.111 & \\
\hline LE4 & 0.043 & 0.073 & 0.064 & 0.083 & 0.903 & 0.126 & 0.088 & 0.035 & \\
\hline EX1 & 0.889 & 0.057 & 0.032 & 0.071 & 0.140 & 0.027 & 0.102 & 0.076 & \multirow{4}{*}{$5.03(1.11)$} \\
\hline EX2 & 0.912 & 0.178 & 0.083 & 0.137 & 0.100 & -0.009 & 0.033 & 0.092 & \\
\hline EX3 & 0.896 & 0.180 & 0.060 & 0.127 & 0.038 & -0.016 & 0.059 & 0.184 & \\
\hline EX4 & 0.832 & 0.190 & 0.114 & 0.217 & 0.072 & 0.039 & 0.000 & 0.160 & \\
\hline IN1 & 0.407 & 0.114 & 0.243 & -0.102 & -0.007 & -0.174 & -0.017 & 0.521 & \multirow{4}{*}{$4.62(0.93)$} \\
\hline IN2 & 0.239 & 0.246 & 0.120 & 0.121 & 0.070 & 0.054 & -0.061 & 0.755 & \\
\hline IN3 & 0.106 & 0.419 & 0.078 & 0.242 & 0.104 & 0.385 & -0.038 & 0.599 & \\
\hline IN4 & 0.309 & 0.318 & 0.245 & -0.051 & 0.005 & 0.097 & 0.121 & 0.652 & \\
\hline RF1 & 0.202 & 0.827 & 0.144 & 0.137 & 0.038 & 0.158 & 0.063 & 0.149 & \multirow{4}{*}{$4.40(1.14)$} \\
\hline RF2 & 0.111 & 0.842 & 0.191 & 0.191 & 0.140 & 0.044 & 0.073 & 0.202 & \\
\hline RF3 & 0.190 & 0.861 & 0.201 & 0.140 & 0.053 & 0.046 & 0.004 & 0.115 & \\
\hline RF4 & 0.153 & 0.828 & 0.190 & 0.014 & 0.101 & -0.001 & 0.119 & 0.204 & \\
\hline PQ1 & -0.021 & 0.293 & 0.627 & 0.250 & -0.057 & -0.139 & -0.019 & 0.346 & \multirow{5}{*}{$4.45(0.94)$} \\
\hline PQ2 & 0.018 & 0.199 & 0.737 & 0.390 & 0.024 & -0.087 & 0.023 & 0.121 & \\
\hline PQ3 & 0.153 & 0.060 & 0.850 & 0.071 & 0.116 & -0.008 & -0.084 & 0.063 & \\
\hline PQ4 & 0.141 & 0.262 & 0.726 & 0.400 & 0.022 & -0.005 & -0.112 & -0.018 & \\
\hline PQ5 & 0.108 & 0.233 & 0.849 & 0.342 & 0.017 & -0.075 & -0.030 & 0.190 & \\
\hline SP1 & 0.085 & 0.081 & 0.286 & 0.812 & 0.018 & 0.003 & -0.110 & 0.013 & \multirow{4}{*}{$4.36(1.38)$} \\
\hline SP2 & 0.183 & 0.121 & 0.123 & 0.860 & 0.146 & -0.050 & 0.053 & 0.161 & \\
\hline SP3 & 0.110 & 0.011 & 0.377 & 0.814 & 0.064 & -0.073 & -0.120 & -0.066 & \\
\hline SP4 & 0.140 & 0.263 & 0.239 & 0.768 & 0.137 & 0.063 & -0.063 & 0.055 & \\
\hline
\end{tabular}


Table 5. Results of convergent validity.

\begin{tabular}{cccc}
\hline Measures & AVE & CR & Cronbach $\alpha$ \\
\hline Coercion & 0.731 & 0.915 & 0.874 \\
Reward & 0.773 & 0.932 & 0.902 \\
Legitimate & 0.808 & 0.944 & 0.920 \\
Information & 0.619 & 0.866 & 0.792 \\
Expert & 0.861 & 0.961 & 0.946 \\
Reference & 0.827 & 0.950 & 0.930 \\
Partnership Quality & 0.699 & 0.902 & 0.856 \\
SCM Performance & 0.781 & 0.934 & 0.907 \\
\hline
\end{tabular}

Table 6. Correlation between constructs.

\begin{tabular}{ccccccccc}
\hline Construct & Coercion & Reward & Legitimate & Information & Expert & Reference & $\begin{array}{c}\text { Partnership } \\
\text { Quality }\end{array}$ & $\begin{array}{c}\text { SCM } \\
\text { Performance }\end{array}$ \\
\hline Coercion & 0.855 & & & & & & & \\
Reward & $0.692^{* *}$ & 0.879 & & & & & \\
Legitimate & $0.444^{* *}$ & $0.400^{* *}$ & 0.899 & & & & \\
Information & 0.108 & $0.177^{*}$ & $0.178^{*}$ & 0.787 & & & \\
$\quad$ Expert & 0.141 & 0.046 & $0.227^{* *}$ & $0.527^{* *}$ & 0.928 & & \\
Reference & $0.175^{*}$ & $0.168^{*}$ & $0.227^{* *}$ & $0.614^{* *}$ & $0.391^{* *}$ & 0.909 & & \\
Partnership & -0.132 & -0.132 & 0.110 & $0.444^{* *}$ & $0.276^{* *}$ & $0.482^{* *}$ & 0.836 & \\
$\quad$ Quality & & & & & & & & \\
$\quad$ SCM & -0.122 & -0.054 & $0.203^{*}$ & $0.283^{* *}$ & $0.324^{* *}$ & $0.343^{* *}$ & $0.619^{* *}$ & 0.884 \\
Performance & & & & & & & \\
\hline
\end{tabular}

The shaded numbers in the diagonal row are square roots of the AVE, * Significant at $\alpha=0.05$ ** Significant at $\alpha=0.01$.

Table 7. VIF and Tolerance.

\begin{tabular}{cccccc}
\hline Construct & Tolerance & VIF & & Tolerance & VIF \\
\hline Coercion & 0.465 & 2.148 & Expert & 0.674 & 1.485 \\
Reward & 0.473 & 2.114 & Reference & 0.539 & 1.857 \\
Legitimate & 0.736 & 1.359 & Partnership Quality & 0.659 & 1.516 \\
Information & 0.483 & 2.068 & Dependent Variable: SCM Performance \\
\hline
\end{tabular}

\section{The Model Structure}

The results of the analysis are presented in Figure 5 and summarized in Table 8. The hypothesis that mediated power influences partnership quality $(\mathrm{H} 1)$ was not statistically significant $(\gamma=0.12, \mathrm{t}=$ 1.10). This finding differs from Benton \& Maloni (2005)'s study results [20], which show that mediated power influences partner companies. However, while coercion $(\gamma=-0.09, t=-1.26)$ and reward $(\gamma=-0.07$, $t=-1.01$ ), which are part of mediated power, did not have a significant influence in the first-order construct analysis, legitimate did have a statistically significant influence $(\gamma=0.13, t=2.38)$. This result implies that it is difficult for mediated power to affect the improvement of partnerships between companies; mediated power is accepted merely to maintain the business relationship. Therefore, even if greater power is held by a partner company, transactions with the partner company must take place through a legal contract rather than attempting coercive influence or influence using a reward.

The hypothesis that mediated power influences SCM performance $(\mathrm{H} 2)$ was not statistically significant $(\gamma=0.15, t=0.09)$. This is different from the argument (Maloni \& Benton, 2000) [21] that mediated power has a short-term influence on system performance. However, while coercion $(\gamma=$ $-0.08, \mathrm{t}=-1.06)$ and reward $(\gamma=0.00, \mathrm{t}=0.00)$, which are components of mediated power, did not significantly influence SCM performance in the first-order construct analysis, legitimate had a statistically significant influence $(\gamma=0.27, \mathrm{t}=2.28)$. As revealed in many previous studies, partnership improvements are essential for SCM performance. However, mediated power does not give partner companies a trust. It only uses the system for business. An SCM system offers greater performance such as stronger company information capacity. Mediated power does not help system performance 
because it causes resistance from partner companies. Therefore, even if greater power is held by a partner company, forcing the partner company to use the system will not improve performance. However, encouraging the use of the system in a legal/institutional relationship is productive.

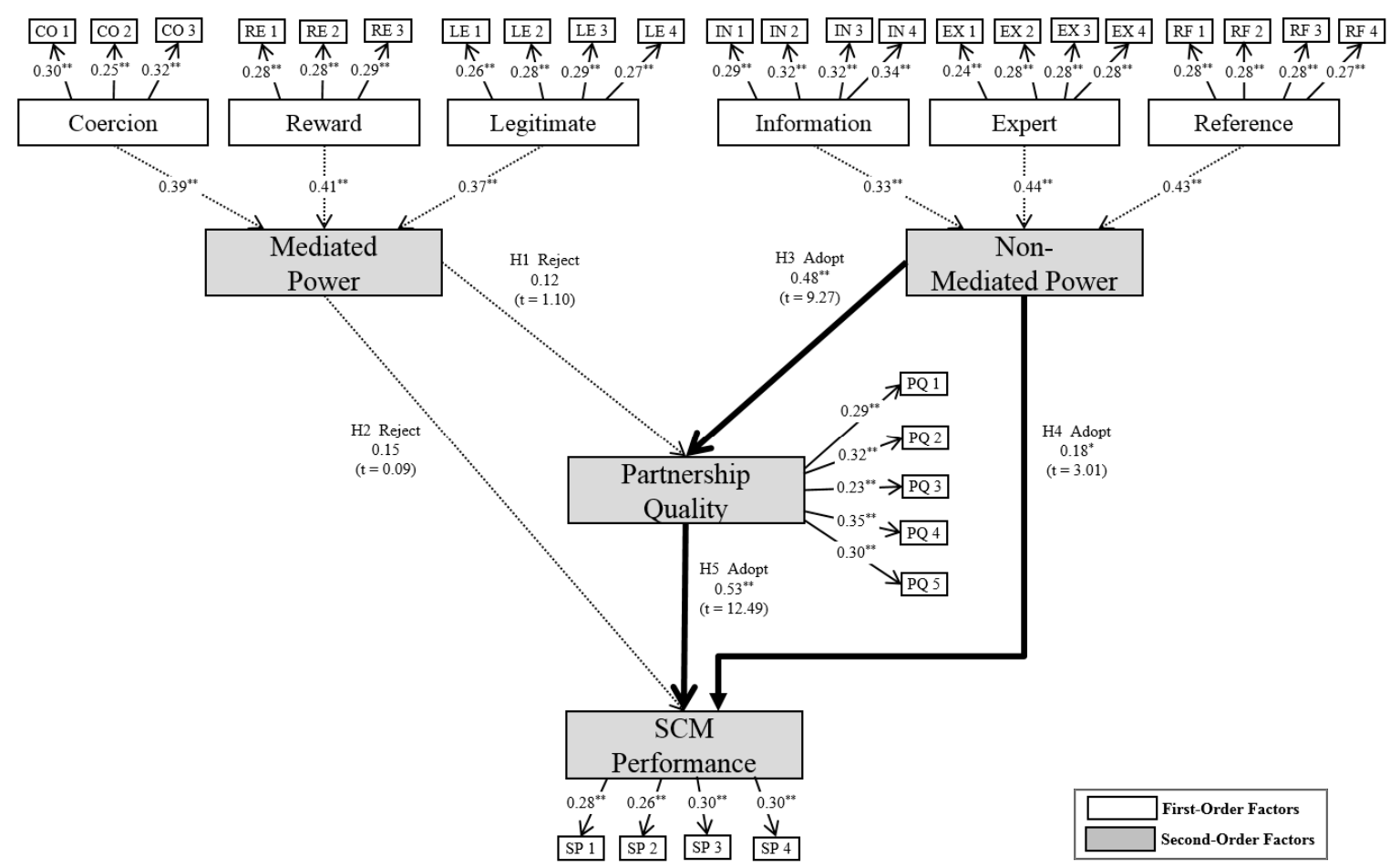

Figure 5. Results of hypothesis testing

Table 8. Coefficients of direct, indirect, and total impacts.

\begin{tabular}{llll}
\hline & & Partnership Quality & SCM Performance \\
\hline \multirow{3}{*}{ Mediated power } & Direct Effect & 0.12 & 0.15 \\
& Indirect Effect & - & 0.02 \\
& Total Effect & & 0.17 \\
& Direct Effect & $0.48^{* *}$ & $0.18^{*}$ \\
Non-mediated power & Indirect Effect & - & $0.20^{* *}$ \\
& Total Effect & $0.48^{* *}$ & $0.38^{* *}$ \\
Partnership Quality & Direct Effect & & $0.53^{* *}$ \\
& Indirect Effect & & - \\
& Total Effect & & $0.53^{* *}$ \\
\hline
\end{tabular}

* Significant at $\alpha=0.05 ; *$ Significant at $\alpha=0.01$.

The hypothesis that non-mediated power influences partnership quality (H3) was statistically significant $(\gamma=0.48, \mathrm{t}=9.27)$. This is in consistent with the argument (Zhao et al., 2013) [9] that nonmediated power enhances partnership. Additionally, information $(\gamma=0.27, \mathrm{t}=2.22)$, expert $(\gamma=0.23$, $\mathrm{t}=2.14)$, and reference $(\gamma=0.28, \mathrm{t}=3.55)$ were shown to have a significant influence on SCM performance in the first-order construct analysis. Therefore, non-mediated power based on a consistent cooperative relationship enhances partnership.

The hypothesis that non-mediated power influences SCM performance (H4) was statistically significant $(\gamma=0.18, t=3.01)$. This is consistent with the argument (Myhr \& Spekman, 2005) [13] that non-mediated power influences successful SCM operation. Information $(\gamma=0.20, t=2.14)$, expert $(\gamma$ $=0.26, t=2.35)$, and reference $(\gamma=0.19, t=2.07)$ have a significant influence on SCM performance in the first-order construct analysis. Thus, non-mediated power based on equality encourages the enhancement of SCM performance.

The hypothesis that partnership quality influences SCM performance (H5) was statistically significant $(\beta=0.53, t=10.23)$. This is consistent with the argument (Kwon \& Suh, 2004) [30] that 
partnership influences successful SCM operation. Maintaining a mutual relationship between partner companies based on trust contributes to enhanced SCM performance.

\section{Conclusions}

This study analyzed the influence of power types on SCM performance. Power types were categorized as mediated power (Coercion, Reward, and Legitimate) and non-mediated power (Information, Expert, and Reference). Therefore, this study examined the influence of mutual and reciprocal human relationships of power types on SCM performance by analyzing partnership quality.

Thus, the main contribution of this study is the analysis of the influence of power types on partnership quality and SCM performance while the study is also a comparison of existing studies.

First, not all mediated powers had a significant influence on partnership quality and SCM performance. The analysis results also showed that mediated power did not have an indirect influence on partnership quality and SCM performance. However, while coercion and reward did not have a significant influence in the first-order construct analysis, legitimate did have a significant influence. This implies that the mediated power of partner companies does not influence partnership quality or SCM performance. Thus, mediated power does not have a beneficial influence on a consistent transactional relationship. However, while coercion and reward did not have an influence, legal/institutional factors did have an influence. To achieve SCM performance, effort must be made to build a mutually dependent environment based on mutual reciprocity rather than mediated power.

Second, all non-mediated powers had a significant influence on partnership quality and SCM performance. These powers all had an influence on partnership quality and SCM performance in the first and second-order construct analysis. The analysis results showed that non-mediated power also had an indirect influence on SCM performance. These study results are consistent with those of Zhao et al. (2013) [9] and Myhr \& Spekman (2005) [13]. The findings show that expertise knowledge, information, and the corporate culture of partner companies greatly enhance partnership. Therefore, the non-mediated power elements between companies must be broadly accepted to increase partnership.

Third, partnership quality had a significant influence on SCM performance. The higher the degree of partnership among companies, the greater the degree of satisfaction, which results in SCM performance. Partnership is proven to be the most important factor for enhancing corporate relationships in the supply chain. This is consistent with the results (Kwon \& Suh, 2004 [30]) of many preceding studies. Based on these study results, we conclude that power types can enhance mutual partnerships; a strategic approach between companies increase SCM performance. We must acknowledge the power of partner companies and find an effective means of managing this power.

The academic and practical contributions of this study are as follows. First, from a practical perspective, we re-examine the power types and partnership relationship between companies that have been overlooked by studies thus far. After assessing the influential power types, we hope that the necessary conditions to establish an enhanced transactional relationship will be implemented.

Second, we studied the power types among organizations and their relationship with SCM performance, for which there has been a lack of sufficient study. While mediated power and nonmediated power types between organizations have a direct and indirect influence on SCM performance, no studies have revealed this in a systematic way. Therefore, this study offers a framework for new studies.

Third, we categorized the existing studies on SCM, where SCM is the CSF, based on whether the study focuses on the application and use of SCM and information technology, the supply chain process integration, SCM partnership, or SCM promotion strategy. Here, we believe this study offers a perspective on the integration of power types.

Although this study offers several positive contributions from an academic and practical standpoint, there are limitations to the study content and methodology. First, this study was unable to consider the characteristics of corporate size and industry type. More significant results are required by increasing the sample size in subsequent studies and subdividing corporate sizes and industry types. We collected samples from a limited number of types of industries. Thus, future studies should consider this and deduce more valuable information. Second, investigating the roles of moderating variables that 
influence SCM performance based on power type must also be presented in subsequent studies. Although some studies attempt this in part, more in-depth study is required. Therefore, an investigative study must be conducted and tools developed that can include and measure many factors. Third, because the sample size of this study was limiting, a larger sample must be collected to support and normalize these study results. Fourth, there is a need to study the differences in the perspective of the companies that execute power and the companies that must comply by categorizing SCM according to sellers and buyers. Lastly, this paper is a study of power, the perceptions of which will differ according to position. In the future, more detailed studies considering position levels are necessary.

Author Contributions: Kwang O. Park, Hwalsik Chang, and Dae Hyun Jung were responsible for the study conception and design and the drafting of the manuscript. Kwang O. Park and Dae Hyun Jung performed the data collection and data analysis. Hwalsik Chang provided statistical expertise. Hwalsik Chang and Dae Hyun Jung made critical revisions to the paper. Kwang O. Park supervised the study.

Conflicts of Interest: The authors declare no conflict of interest.

\section{References}

1. Power, D. Supply chain management integration and implementation: A literature review. Supply. Chain. Manag. 2005, 10, 252-263.

2. Lee, J.S.; Kim, S.K.; Lee, S.Y. Sustainable supply chain capabilities: Accumulation, strategic types and performance. Sustainability. 2016, 8, 503.

3. Murata, K. Analyzing environmental continuous improvement for sustainable supply chain management: Focusing on its performance and information disclosure. Sustainability, 2016, 8, 1256.

4. Simatupang, T.M.; Sridharan, R. The collaborative supply chain. Int. J. Logist. Manag. 2002, 13, 15-30.

5. Geimer, H.; Schulze, F.; Vickers, P.; Hassan. M. Managing Complexity in Global Supply Chains; PRTM Management Consultants: Waltham, MA, USA, 2004.

6. Tony, F.; Debra, H.; Kevin, M. The AMR Research Supply Chain Top 25 for 2009; Advanced Market Research: Boston, USA, 2009.

7. Derocher, R.P.; Kilpatrick, J. Six supply chain lessons for the Millennium. Supply Chain Manag. Rev. 2000, 4, 34-40.

8. Bakker, E.; Zheng, J.; Knight, L.; Harland, C. Putting e-commerce adoption in a supply chain context. Int. J. Oper. Prod. Manag. 2008, 28, 313-330.

9. Zhao, L.; Huo, B.; Sun, L.; Zhao, X. The impact of supply chain risk on supply chain integration and company performance: A global investigation. Supply Chain Manag. 2013, 18, 115-131.

10. Lane, M.; Van Der Vyver, G. Partnership Quality in IT Outsourcing-A Mixed Methods Review of Its Measurement. In Proceedings of ACIS 2005, Sydney, Australia, 29 November-2 December 2005.

11. Kozan, M.K.; Wasti, S.N.; Kuman, A. Management of buyer-supplier conflict: The case of the turkish automotive industry. J. Bus. Res. 2006, 59, 662-670.

12. Power, D.J.; Sohal, A.S. Implementation and usage of electronic commerce in managing the supply chain: A comparative study of ten Australian companies. Benchmarking Int. J. 2002, 9, 190-208.

13. Myhr, N.; Spekman, R.E. Collaborative supply chain partnerships built upon trust and electronically mediated exchange. JBIM. 2005, 20, 179-186.

14. Bednarska, M.A. Complementary person-environment fit as a predictor of job pursuit intentions in the service industry. Contemp. Econ. 2016, 10, 27-38.

15. Ke, W.; Liu, H.; Wei, K.K.; Gu, J.; Chen, H. How do mediated and non-mediated power affect electronic supply chain management system adoption? The mediating effects of trust and institutional pressures. Decis. Support Syst., 2009, 46, 839-851.

16. Harland, C.M.; Lamming, R.C.; Zheng, J.; Johnsen, T.E. A taxonomy of supply networks. JSCM. 2001, 37, $21-27$.

17. Robert, H. Software Piracy on the Internet: A Threat to Your Security; Business Software Alliance: Washington, DC, USA, 2009.

18. French, J.R.; Raven, B.; Cartwright, D. The Bases of Social Power; University of Michigan: Ann Arbor, MI, USA, 1959, pp. 311-320.

19. Flynn, B.B.; Zhao, X.; Huo, B.; Yeung, J.H.Y. We've got the power! How customer power affects supply chain relationships. Bus. Horizons. 2008, 51, 169-174.

20. Benton, W.C.; Maloni, M. The influence of power driven buyer/seller relationships on supply chain satisfaction. J. Oper. Manag. 2005, 23, 1-22. 
21. Maloni, M.; Benton, W.C. Power influences in the supply chain. J. Bus. Logist. 2000, 21, 49-74.

22. Sahin, F.; Robinson, E. Flow coordination and information sharing in supply chains: review, implication, and directions for future research. Decis. Sci. 2002, 33, 505-536.

23. Mentzer, J.T.; Foggin, J.H.; Golicic, S.L. Collaboration: The enablers, impediments and benefits. Supply Chain Manag. Rev. 2000, 4, 52-58.

24. Homans, G. C. Social behavior as exchange. Am. J. Sociol. 1958, 63, 597-606.

25. Lee, J.N.; Kim Y.G. Effect of partnership quality on IS outsourcing success: Conceptual framework and empirical validation. J. Manag. Inform. Syst. 1999, 15, 29-61.

26. Moorman, C.; Deshpande, R.; Zaltman, G. Factors affecting trust in market research relationships. J. Marketing. 1993, 57, 81-101.

27. Bouncken, R.B.; Pesch, R.; Reuschl, A. Copoiesis: Mutual knowledge creation in alliances. J. Innov. Knowl. 2016, 1, 44-50.

28. Quinn, J.B. Outsourcing innovation: The new engine of growth. MIT Sloan Manag. Rev. 2000, 41, 13-28.

29. Lenells, J.; Stea, D.; Foss, N.J. Optimal contracting under adverse selection: The implications of mentalizing. Contemp. Econ. 2015, 9, 215-232.

30. Kwon, I.W.; Suh, T. Factors affecting the level of trust and commitment in supply chain relationship. JSCM. 2004, 40, 4-14.

31. Morgan, R.M.; Hunt, S.D. The commitment-trust theory of relationship marketing. J. Mark. 1994, 58, $20-38$.

32. Frohlich, M.T.; Westbrook, R. Arcs of integration: An international study of supply chain strategies. J. Oper. Manag. 2001, 19, 185-200.

33. Ozkan-Canbolat, E.; Beraha, A. Configuration and innovation related network topology. J. Innov. Knowl. 2016, 1, 91-98.

34. Hoque, Z.; James, W. Linking balanced scorecard measures to size and market factors: Impact on organizational performance. J. Account. Res. 2000, 12, 1-17.

35. Banker, R.D.; Potter, G.; Srinivasan D. An empirical investigation of an incentive plan that includes nonfinancial performance measures. Account. Rev. 2000, 75, 65-92.

36. De Felice, F.; Petrillo, A.; Autorino, C. Development of a framework for sustainable outsourcing: Analytic Balanced Scorecard Method (A-BSC). Sustainability. 2015, 7, 8399-8419.

37. Najmi, M.; Kehoe, D. The role of performance measurement systems in promoting quality development beyond ISO 9000. Int. J. Oper. Prod. Manag. 2001, 21, 159-172.

38. Chin, W.W.; Marcolin, B.L.; Newsted, P.R. A partial least squares latent variable modeling approach for measuring interaction effects: Results from a Monte Carlo simulation study and an electronic-mail emotion/adoption study. Inf. Syst. Res. 2003, 14, 189-217.

39. Bock, G.W.; Zmud, R.W.; Kim, Y.G.; Lee, J.N. Behavioral intention formation in knowledge sharing: Examining the roles of extrinsic motivators, social-psychological forces, and organizational climate. Manag. Inf. Syst. Q. 2005, 29, 87-111.

40. Hair, J.F.; Black, W.C.; Babin, B.J.; Anderson, R.E.; Tatham, R.L. Multivariate Data Analysis, 6th Ed.; Pearson Education: Upper Saddle River, NJ, USA, 2006.

(C) 2017 by the authors; licensee Preprints, Basel, Switzerland. This article is an open access article distributed under the terms and conditions of the Creative Commons by Attribution (CC-BY) license (http://creativecommons.org/licenses/by/4.0/). 